\title{
No, the Firing Squad Is Not Better than Lethal Injection: A Response to Stephanie Moran's A Modest Proposal
}

\author{
Michael Conklin*
}

\section{CONTENTS}

INTRODUCTION

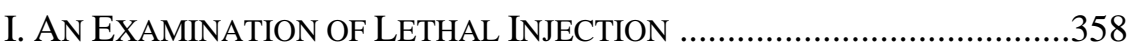

A. Burning Sensation from Lethal Injection......................................358

B. Lethal Injection as Lengthy and Painful Death...........................359

C. Administering IVs as Unconstitutional..........................................359

II. FIRING SQUADS: A Viable Alternative.......................................360

A. Inmates Prefer Firing Squads .....................................................360

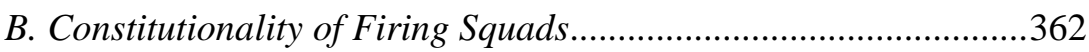

C. Unexamined Problems with Moran's Analysis of

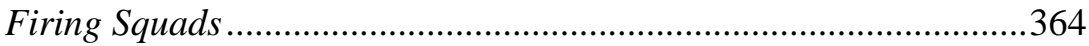

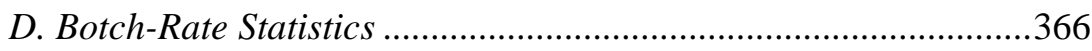

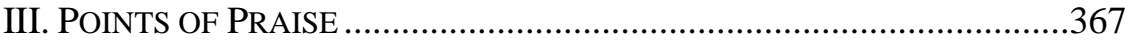

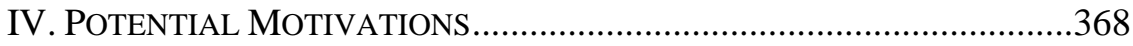

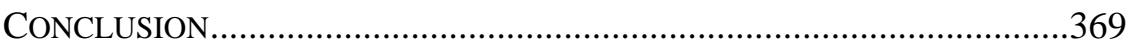

\section{INTRODUCTION}

In the article A Modest Proposal: The Federal Government Should Use Firing Squads to Execute Federal Death Row Inmates, ${ }^{1}$ Stephanie Moran argues that the firing squad is the only execution method that meets the requirements of the Eighth Amendment. ${ }^{2}$ In order to make her case, Moran unjustifiably overstates the negative aspects of lethal injection while understating the negative aspects of firing squads. The entire piece

* Powell Endowed Professor of Business Law, Angelo State University.

1. Stephanie Moran, A Modest Proposal: The Federal Government Should Use Firing Squads to Execute Federal Death Row Inmates, 74 U. MiAmi L. REV. 276 (2019).

2. Id. 
is predicated upon assumptions that are not only unsupported by the evidence but often directly refuted by the evidence. This Essay critically analyzes Moran's claims regarding the alleged advantages of the firing squad over lethal injection. Topics covered include: the alleged burning sensation from lethal injection, length of lethal injection pain, constitutionality of administering an intravenous injection (IV), inmate preferences in method of execution, constitutionality of firing squads, overlooked firing squad safety measures, and deceptive botch rate statistics. Additionally, potential motivations for why one would want to promote the firing squad over lethal injection are examined.

\section{AN EXAMINATION OF LETHAL INJECTION}

\section{A. Burning Sensation from Lethal Injection}

Moran makes five references to the claim that inmates feel intense burning from lethal injection. ${ }^{3}$ But these claims are all based on the single occurrence of one inmate, Michael Lee Wilson, who exclaimed, "I feel my whole body burning." 4 Based on this statement alone, Moran concludes that pentobarbital was the cause of Wilson's pain. ${ }^{5}$ The likelihood of a drug causing a single inmate ${ }^{6}$ to feel intense burning all over his body, while every other lethally injected inmate does not, is never addressed by Moran.

This claim not only lacks persuasive, anecdotal evidence but also has no basis in science. The drug that Moran claims is responsible for the burning sensation, pentobarbital, ${ }^{7}$ is used for anesthesia in surgeries and to treat insomnia. ${ }^{8}$ It is also the standard, physician-assisted suicide drug protocol in the Netherlands ${ }^{9}$ and the second-most common used in Oregon. ${ }^{10}$ Burning sensation is not listed as a known side effect, ${ }^{11}$ and this

3. $I d$. at $277,285,287,300,302$.

4. Id. at $277,287$.

5. Id. at 287.

6. Moran does cite to an inmate who claimed to "taste it in my throat." Id. at 300 n.198. But only the exclamation by Michael Lee Wilson is presented as evidence of someone who felt burning all over.

7. Id. at 287.

8. Pentobarbital, ENCYC. BRITANNICA, https://www.britannica.com/science/pentobarbital [https://perma.cc/9QYC-KCLH].

9. See David Jolly, Push for the Right to Die Grows in the Netherlands, N.Y. TIMES (Apr. 2, 2012), https://www.nytimes.com/2012/04/03/health/push-for-the-right-to-die-grows-in-thenetherlands.html [https://perma.cc/4TUT-JCCD].

10. Jennifer Fass \& Andrea Fass, Commentary, Physician-Assisted Suicide: Ongoing Challenges for Pharmacists, 68 AM. J. HEALTH-SYS. PhARMACY 846, 847 (2011).

11. John P. Cunha, Nembutal Side Effects, RXLiST (Nov. 29, 2017), https://www.rxlist.com/ nembutal-side-effects-drug-center.htm [https://perma.cc/DC3U-9U44]. 
author was unable to find any reported case-other than Wilson-of anyone reporting burning in association with pentobarbital.

It is, at best, misguided to extrapolate from the Michael Lee Wilson execution that pentobarbital causes burning. It also demonstrates the lengths that are necessary to make the firing squad appear preferable to lethal injection.

\section{B. Lethal Injection as Lengthy and Painful Death}

Throughout the article, Moran claims that lethal injection often leads to "a lengthy, painful death." 12 Her evidence to support this claim is tenuous at best. At one point she provides the example of Thomas Arthur, who--Moran claims - “ "died a lengthy, painful death."13 Moran's evidence to support this claim is a newspaper article that reports how Arthur received lethal injection and then "[a]bout half an hour later, he was pronounced dead." 14 The source provides not even an intimation that Arthur experienced pain, no less "lengthy" pain. Furthermore, the Supreme Court has held that lethal injection does not violate the Constitution, ${ }^{15}$ which protects against "lingering death." ${ }^{16}$ In fact, neurobiologist Harold Hillman studied the potential for pain in various execution methods and concluded that "[a]11 of the methods used for executing people, with the possible exception of intravenous injection, are likely to cause pain." 17

\section{Administering IVs as Unconstitutional}

Even setting aside the baseless claim of lethal injection causing burning sensations, Moran claims that just the process of inserting the IV can be unconstitutional. ${ }^{18}$ This conclusion is based on how "[m]any issues arise" when inserting an IV, especially for overweight and drug-addicted inmates. ${ }^{19}$ Anyone who has experienced donating blood where the phlebotomist improperly inserts the IV on the first attempt can testify that it is not a pleasurable experience. But to claim that this level of discomfort

12. Moran, supra note 1 , at 308.

13. Id.

14. Jenny Jarvie, Murderer Known as 'Houdini of Death Row' Executed in Alabama, L.A. TIMES (May 25, 2017), https://www.latimes.com/nation/la-na-alabama-houdini-execution-20170525htmlstory.html [https://perma.cc/LG5T-PNV4].

15. Baze v. Rees, 553 U.S. 35, 63 (2008) (holding that Kentucky's use of lethal injection does not violate the Eighth Amendment).

16. In re Kemmler, 136 U.S. 436, 447 (1890) ("Punishments are cruel when they involve torture or a lingering death .....").

17. Harold Hillman, The Possible Pain Experienced During Execution by Different Methods, 22 PERCEPTION 745, 751 (1993) (evaluating death by firing squad as one of the methods).

18. Moran, supra note 1 , at 301.

19. Id. 
rises to unconstitutionally cruel and unusual punishment is hyperbolic at best. The government may require blood tests for drunk-driving investigations ${ }^{20}$ for parole,${ }^{21}$ or even to acquire a marriage certificate. ${ }^{22}$

Related to the issue of administering IVs, Moran claims that "[d]ue to the code of medical ethics, doctors are advised against participating in executions, which results in non-medical professionals attempting to insert IVs." 23 This is a deceptive statement. It is true that the code of medical ethics advises against participating in executions; however, physicians do frequently participate in the lethal injection of inmates. ${ }^{24}$ In fact, doctors created the original combination of drugs used in lethal injection and "advised legislatures, courts and prisons about the types and amounts of lethal injection drugs that should be used." 25

\section{FIRING SQUADS: A Viable Alternative}

\section{A. Inmates Prefer Firing Squads}

Moran claims that "inmates seem to believe that lethal injection is more painful and far less humane than death by firing squad." 26 But the citation presented to support this claim does no such thing. It is simply a newspaper article on the execution of one inmate, Stephen Michael West, who chose to be electrocuted rather than lethally injected. ${ }^{27}$ An explanation as to how this supports the claim that inmates "believe that

20. Mitchell v. Wisconsin, 139 S. Ct. 2525, 2539 (2019) (holding that, in some instances, a warrant is not even required to obtain a blood test).

21. S.D. Dep'T OF CORR., Policy 1.3.A.8., Offender Drug Testing, SAnctions \& TREATMENT (2016), https://doc.sd.gov/about/policies/documents/OffenderDrugTestingSanctionsand Treatment.pdf [https://perma.cc/WS3L-ZEB6] ("In addition to a PBT test, an offender may be required to submit to a urinalysis (UA) or blood test.").

22. Chart: State Marriage License and Blood Test Requirements, NoLO, https://www.nolo.com/ legal-encyclopedia/chart-state-marriage-license-blood-29019.html [https://perma.cc/32Y7-JHP4].

23. Moran, supra note 1 , at 301.

24. Deborah W. Denno, The Firing Squad as "A Known and Available Alternative Method of Execution" Post-Glossip, 49 U. Mich. J.L. REFORM 749, 769 (2016) ("Doctors and other medical professionals have long participated in carrying out all execution methods, most particularly lethal injection.”); Atul Gawande, The Excellent Execution: Why Physicians Participate in Lethal Injection of Prisoners, HARV. Univ. EDMOND J. SAFRA CTR. FOR ETHICS (Feb. 27, 2006), https://www.ethics.harvard.edu/event/excellent-execution-why-physicians-participate-lethalinjection-prisoners [https://perma.cc/2S3V-AD3Z].

25. Denno, supra note 24, at 769 .

26. Moran, supra note 1 , at 304.

27. Adam Tamburin, Mariah Timms \& Matt Lakin, Tennessee Executes Stephen Michael West Dies by Electric Chair, TENNESSEAN (Aug. 16, 2019), https://www.tennessean.com/story/ news/2019/08/15/tennessee-execution-stephen-michael-west-dies-electric-chair/2009390001/ [https://perma.cc/U9RZ-TAUS]. 
lethal injection is more painful and far less humane than death by firing squad" is never provided. ${ }^{28}$

Even if Stephen Michael West chose the firing squad over lethal injection - while far more defensible than what was presented-this would still do little to support Moran's claim that lethal injection is more painful and far less humane. The opinion of a single death row inmate, who has no medical expertise and suffers from a number of severe mental illnesses, ${ }^{29}$ is largely irrelevant in the matter.

Setting aside the issue that death row inmates' preferences are not the standard for determining what punishments are unconstitutionally cruel and unusual, Moran's claim is resoundingly refuted by the evidence. Statistics from the three states that still allow inmates to choose firing squads (Oklahoma, Mississippi, and Utah) ${ }^{30}$ unequivocally show that inmates do not prefer firing squads.

A list of executions in Oklahoma for the last 100 years shows no inmate has ever chosen death by firing squad. ${ }^{31}$ Likewise, no inmate in Mississippi has chosen the firing squad in the last forty years. ${ }^{32}$ In Utah, only two inmates chose to be executed by the firing squad in the last forty years. ${ }^{33}$ Additionally, the two inmates' reasons for choosing execution by firing squad appear to not be due to the perception that lethal injection is "more painful and far less humane." John Albert Taylor elected to be executed by a firing squad, but his decision appears to be the result of a desire to embarrass the state of Utah. ${ }^{34}$ Ronnie Lee Gardner - the other inmate in Utah who chose the firing squad - did so based partially on his Mormon faith. ${ }^{35}$ The use of the firing squad in Utah has a storied

28. Moran, supra note 1 , at 304.

29. Tamburin, Timms \& Lakin, supra note 27.

30. Dustin Barnes, What Methods of Execution Are Still in Practiced in the United States?, TENNESSEAN (Aug. 15, 2019), https://www.tennessean.com/story/news/crime/2018/10/09/methodsexecution-state-electric-chair-firing-squad-hanging-gas-chamber/1576763002/ [https://perma.cc/ CT75-2M6Z].

31. Execution Statistics, OKLA. DEP'T CORR., http://doc.ok.gov/execution-statistics [https:// perma.cc/7TPH-6JNX].

32. Mississippi and the Death Penalty, MISS. DEP'T CORR., https://www.mdoc.ms.gov/DeathRow/Pages/Mississippi-Death-Penalty.aspx [https://perma.cc/SHW6-WJ5E].

33. Juan Ignacio Blanco, U.S.A. Executions - 1977-Present, DEATHPENALTYUSA, https://deathpenaltyusa.org/usa/state/utah.htm [https://perma.cc/HUN2-2CB6].

34. A Look at Utah's Most Infamous Executions, KSL.COM (June 13, 2010), https://www.ksl.com/article/11134823 [https://perma.cc/ZVU7-JPYC]. He also refused to be sedated. Id.; see also Amy Donaldson, Firing Squad Carries Out Execution, DESERET News (Jan. 26, 1996), https://www.deseret.com/1996/1/26/19221501/firing-squad-carries-out-execution [https://perma.cc/ 27UQ-RSQN].

35. Amy Donaldson, Inmate Threatens to Sue if State Won't Let Him Die by Firing Squad., DESERET NEwS (Feb. 9, 1996), https://www.deseret.com/1996/2/9/19224129/inmate-threatens-tosue-if-state-won-t-let-him-die-by-firing-squad [https://perma.cc/88U8-PN3Z]. 
connection to the state's Mormon history. ${ }^{36}$ Mormonism's "blood atonement" doctrine teaches that some sin is so heinous that, like Jesus, the perpetrators must have their blood spilled in order to obtain forgiveness. ${ }^{37}$ Lethal injection does not allow for blood atonement, while the firing squad does. Accordingly, despite Moran's assertion, there is not a single, clear example of an inmate executed by firing squad who chose the method over lethal injection based on a pain-mitigation strategy.

Even Moran's more modest claim that some inmates have requested death by firing squad based on a stated attempt to reduce pain ${ }^{38}$ — while technically true - is misleading. Inmates in Alabama, Ohio, Tennessee, and Texas have requested death by firing squad. ${ }^{39}$ Because these states do not offer the firing squad as an option, these inmates are requesting something that they know is not available. Simply put, when inmates have an actual option of choosing to be executed by firing squad, they overwhelmingly choose not to. And the few who do appear to choose death by firing squad do so, not because of a pain-reduction strategy, but for other reasons. Moran's conclusion that "inmates seem to believe that lethal injection is more painful and far less humane than death by firing squad" 40 is not only completely baseless but also contradicted by the evidence.

This is likely why Justice Sonia Sotomayor made the far more limited claim that "[i]n the future ... some inmates may suggest the firing squad as an alternative [to lethal injection]." ${ }^{41}$ It is highly peculiar that the people who claim firing squads are less painful and more humane than lethal injection are people like Moran and inmates in states that do not allow firing squads -i.e., people who will not have to face the consequence of their stated preference. Meanwhile, the people whose opinion on the firing squad could actually result in them enduring execution by one overwhelmingly believe that it is not less painful than lethal injection.

\section{B. Constitutionality of Firing Squads}

Moran appears to assume that death by firing squad does not violate the Eighth Amendment's protection against cruel and unusual punishment. However, the Supreme Court has never ruled on this issue, and it is unclear how it would if it came up today. Technically, the Supreme Court upheld a sentence of death by firing squad in Wilkerson v. Utah. ${ }^{42}$ But the facts

36. Denno, supra note 24 , at 788.

37. Id. at $788-89$ (note that the Mormon church officially revoked the teaching of blood atonement in 1978).

38. Moran, supra note 1 , at 304.

39. Id.

40. Id.

41. Glossip v. Gross, 576 U.S. 863, 976 (2015) (Sotomayor, J., dissenting).

42. See Wilkerson v. Utah, 99 U.S. 130, 137 (1878). 
about that case did not assess whether death by firing squad was cruel and unusual punishment; the plaintiff did not raise, and the Court did not review, that issue. Rather, the case revolved around the application of a Utah statute that authorized first-degree murderers to be executed. ${ }^{43}$ Furthermore, the case was decided in 1878, over eighty years before the incorporation of the Eighth Amendment and therefore over eighty years before the application of the Eighth Amendment to the states. ${ }^{44}$

The Supreme Court decision of Glossip v. Gross requires that an "alternative method" of execution be "known," "available," and "entail[] a lesser risk of pain." ${ }^{\prime 5}$ Death by firing squad is certainly known and available, but it is unlikely that it entails a lesser risk of pain. In contrast to the nebulous question of whether the Supreme Court would uphold death by firing squad, lethal injection has been upheld multiple times in the twenty-first century. ${ }^{46}$

Moran points to claims that the pain experienced by those executed by firing squad "may be comparable to being punched in the chest." 47 However, this is only a best-case scenario. "Persons hit by bullets feel as if they have been punched-pain comes later if the victim survives long enough to feel it." 48

The United Kingdom's view of whether death by firing squad is permissible may further undermine Moran's assumption of its constitutionality. In 1953, the Royal Commission on Capital Punishment emphatically concluded that death by firing squad was an inadequate method of execution. ${ }^{49}$ The Commission came to this conclusion because death by firing squad "needs a multiplicity of executioners and it does not possess even the first requisite of an efficient method, the certainty of causing immediate death." ${ }^{50}$ Given the similarities in the legal systems of the United Kingdom and the United States, it is quite plausible the Supreme Court may come to the same conclusion as the commission and hold death by firing squad as unconstitutional if the issue is raised.

43. Id. at 130

44. See, e.g., Robinson v. California, 370 U.S. 660, 666 (1962).

45. Glossip, 576 U.S. at 867 (citing Baze v. Rees 553 U.S. 35, 61 (2008) (plurality opinion)).

46. See, e.g., id.; Baze, 553 U.S. at 63.

47. Moran, supra note 1, at 299.

48. Harold Hillman, The Possible Pain Experienced During Execution by Different Methods, 22 PERCEPTION 745, 745 (1993) (emphasis added).

49. Royal COMm'N ON CAP. Punishment, Royal COMmission on CAPITAL Punishment 1949-1953 REPORT, 1953, Cmd. 8932, at 249 (UK).

50. Id. 


\section{Unexamined Problems with Moran's Analysis of Firing Squads}

The firing squad protocol suggested by Moran involves five shooters. ${ }^{51}$ This drastically increases the number of people directly responsible for the death of the inmate. This is problematic because many executioners report experiencing post-traumatic stress disorder. ${ }^{52}$

Moran touts the training that the firing squad team is required to undertake. ${ }^{53}$ For example, they would be required to pass a marksmanship test. ${ }^{54}$ But shooting a target and shooting a human have very different psychological effects. Some of the marksmen's nerves may cause them to become shaky when faced with a human target. Even at twenty-five feet away-the distance suggested by Moran ${ }^{55}$ —slight muzzle deviations caused from nervousness could result in a bullet that is significantly off target. Furthermore, there is a chance that one or more of the five shooters will, for a variety of potential reasons, be rendered incapable of pulling the trigger in the heat of the moment. Moran dismisses the issue of botched firing squad executions by pointing out that these errors can be "easily remedied" by further restraining the inmate and implementing "more intense training for executioners." 56 Of course, these after-the-fact remedies will be of little consolation for the initial inmate whose execution was botched. Furthermore, it is unclear how further restraining the target and increasing the intensity of practice shots would ensure against stressinduced errors by the marksmen.

Moran continues to tout the benefits of firing squads by stating that "a purposeful miss would be an obvious infliction of suffering, whereas errors in other methods may be more easily covered up as accidents." 57 How Moran proposes to tell the difference between a "purposeful" miss and an accidental one - and which of the five executioners the miss came from-is never addressed.

Moran claims that the risk of error in firing squad executions is "minimal" because there are "at least four bullets coming for the inmate." 58 Even if one assumes that all four bullets will always hit the inmate, it is

51. Moran, supra note 1, at 290, 297 (“[T]he federal government can look to Utah's technical manual ...."’).

52. Robert T. Muller \& Veerpal Bambrah, Prison Executioners Face Job-Related Trauma, PSYCH. TODAY (Oct. 11, 2018), https://www.psychologytoday.com/us/blog/talking-abouttrauma/201810/prison-executioners-face-job-related-trauma [https://perma.cc/5PYF-LCSL].

53. Moran, supra note 1 , at 290.

54. Id.

55. Id. at 288-89.

56. Id. at 303 .

57. Id.

58. $I d$. at 299. One of the five executioners is given a rifle with blanks in it. $I d$. at 290. 
not uncommon for someone to survive being shot four or more times. ${ }^{59}$ One man survived being shot roughly twenty times. ${ }^{60}$ And these examples only include people who survived being shot four or more times. One must also consider the rate at which people shot four times ultimately die-but only after a period of excruciating pain.

Moran discusses the Supreme Court's decision in Glossip but seems to miss the case's relevance to the lethal injection versus firing squad debate. The prisoners in Glossip were unable to "identify a known and available method of execution that presented a substantially less severe risk of pain." ${ }^{61}$ The inmates in Glossip were on death row in Oklahoma, a state that allows the firing squad. ${ }^{62}$ The inmates' inability to identify an execution method that entails a lesser risk of pain than lethal injection was essentially acknowledgment that lethal injection is the safest available method of execution when compared to the alternatives - including the firing squad.

Another issue not addressed by Moran is how death by firing squad is to be administered on an inmate who physically resists. Once the inmate is secured to the chair, restraints keep him relatively still. But how do correctional officers force an unwilling inmate into the restraints? If the answer is to first anesthetize the inmate, then this calls into question the claimed advantages of the firing squad over lethal injection. Wyoming's 2015 bill to introduce death by firing squad required anesthetization that rendered the inmate unconscious before being shot. ${ }^{63}$ Commentators have noted that this requirement "appeared to resemble some aspects of lethal injection." ${ }^{64}$

The procedures in place for firing squad executions shed light on how the practice is far from an exact science. For example, backup rifles and ammunition are required. ${ }^{65}$ Also, within three minutes after the first four shots, "[i]f the condemned inmate appears to be unconscious," 66 a physician is to check the inmate's vital signs every sixty seconds for ten

59. See John Eligon, One Bullet Can Kill, but Sometimes 20 Don't, Survivors Show, N.Y. TIMES (Apr. 3, 2008), https://www.nytimes.com/2008/04/03/nyregion/03shot.html [https://perma.cc/KP79KKN4].

60. See id. Note that these examples refer to real-world shootings and not executions.

61. Glossip v. Gross, 576 U.S. 863, 875 (2015).

62. See Barnes, supra note 30; Glossip, 576 U.S. at 867.

63. Denno, supra note 24 , at 780-81.

64. Id. at 781 .

65. Nadia Pflaum, How Utah's Execution by Firing Squad Works, STANDARD-EXAMINER (Apr. 10, 2017), https://www.standard.net/police-fire/courts/how-utah-s-execution-by-firing-squad-works/ article_1eeffdaf-a792-5f1e-9de3-552ea665e989.html [https://perma.cc/P8M8-KSA6].

66. UtAh DEP'T OF CORR., DEATH PENALTy PROCEDURES: TECHniCAL MANUAL 10 (2010); see also Curtis Waltman, Utah Department of Corrections Releases Technical Manual for Their Execution Process, MuCKROCK (Mar. 30, 2017), https://www.muckrock.com/news/archives/2017/mar/30/utahdeath-penalty-manual/ [https://perma.cc/JFL8-TB8K]. 
minutes. ${ }^{67}$ If the inmate is still alive after this, a second "volley" occurs. ${ }^{68}$ Within three minutes of this, the physician again checks the inmate's vital signs until the inmate can be certified dead. ${ }^{69}$ The complexity and uncertainty of this procedure is in direct contradiction with Moran's claim that this method of execution is less cruel and unusual — an inmate's death in the first round is not certain, and the inmate may be subjected to ten additional minutes of suffering before the second volley occurs.

Given the article's aim at presenting the firing squad as superior to lethal injection, it is odd that Moran overlooks an obvious fix for the problem of human error in firing squads. Namely, because the chair that the inmate is strapped to is fixed in place, the rifles could simply be fixed in place, thus ensuring perfect aim. Furthermore, this would avoid the problem of determining which gunman is to blame in the instance of a missed shot. A fixed apparatus was successfully implemented in a firing squad execution over one hundred years ago, ${ }^{70}$ it involved three mounted rifles that were fired upon the cutting of three strings. ${ }^{71}$

\section{Botch-Rate Statistics}

Moran's claim that the botch rate for death by firing squad in the United States is a flawless $0 \%{ }^{72}$ is highly peculiar, as there are documented examples of botched firing squad executions. Wallace Wilkerson took fifteen to twenty minutes to die after being shot by a firing squad. ${ }^{73}$ In the execution of Eliseo Mares, all four executioners missed the intended target but still hit his body, causing him to eventually die due to blood loss. ${ }^{74}$

Almost as peculiar as claiming that firing squads have a $0 \%$ botch rate in the United States is Moran's claim that the botch rate of lethal injection is $7.12 \% .^{75}$ This statistic is the result of research from prominent abolitionist Austin Sarat. ${ }^{76}$ Sarat's subjective determinations as to what constitutes a "botched" lethal injection include the following:

- When prison personnel opened the curtains too soon during the execution; ${ }^{77}$

67. Pflaum, supra note 65.

68. Id.

69. Id.

70. Phillip I. Earl, Nevada's Execution Machine, NeVADAN, Dec. 3, 1972, at 3.

71. Id.

72. Moran, supra note 1, at 283.

73. Denno, supra note 24, at 787.

74. Id.

75. Moran, supra note 1 , at 283.

76. Austin SARAt, GRUESOME SPeCtaCles: BotChed EXECUTIONS AND AMERICA's DeATH PENALTY 177 (2014).

77. Id. at 210 . 
- An inmate who "[l]oudly proclaim[ed] his innocence and ... resisted prison guards' efforts to transport him from his cell"; ;

- An inmate who unsuccessfully tried to get out of his restraints $;^{79}$

- An inmate who coughed, gasped, and cried "as the needle was inserted into his arm"; 80

- An inmate whose execution resulted in "[b]lood oozing from the injection site saturat[ing] a paper towel during the procedure." 81

A large percentage of the lethal injection executions that Sarat categorizes as "botched" simply involve the claim that prison staff took too long to administer the IV. ${ }^{82}$ Sometimes, an inmate who shows no signs of pain is nevertheless determined to be the victim of a "botched" execution solely because the amount of time that passed between the injection and the official determination of death was determined by Sarat to be too long. ${ }^{83}$ These periods of time can be as short as fourteen minutes. ${ }^{84}$ Or, as Sarat refers to them, "a full fourteen minutes." 85 Unfortunately, Sarat's problematic botch-rate calculations are prevalent in death penalty literature ${ }^{86}$ and have even been cited by the Supreme Court. ${ }^{87}$

\section{POINTS OF PRAISE}

It should be noted that while this response focuses on areas of critique, Moran does provide some valid points to support her conclusion. For example, an overriding theme of the article is that the Constitution's protection against cruel and unusual punishment should be based on the inmate's point of view and not that of an execution observer. ${ }^{88}$ Decisions about the constitutionality of executions should not be based on gut-level reactions of how execution methods are perceived. Rather, decisions should rely on a more objective, evidence-based approach analyzed from the inmate's frame of reference.

78. Id. at 206-07.

79. Id. at 202-03.

80. Id . at 202. Since the behavior occurred while the needle was being inserted, it clearly was not a result of the drugs not yet injected into his body.

81. Id. at 209.

82. Id. at $198-210$.

83. Id.

84. Id. at 207.

85. Id.

86. In addition to Moran's article, see also Denno, supra note 24, at 781.

87. See, e.g., Glossip v. Gross, 576 U.S. 863, 975-76 (2015) (Sotomayor, J., dissenting).

88. See Moran, supra note 1, at 279, 281. 
Additional valid points made by Moran include how firing squads avoid issues related to lethal injection, such as administering the IV to an obese or drug addicted inmate. ${ }^{89}$ Also, the logistical problem of obtaining lethal injection drugs directly from suppliers or from compounders is avoided when firing squads are used because rifles and ammunition are unlikely to become unavailable in the United States. ${ }^{90}$

\section{POTENTIAL MOTIVATIONS}

It is a highly subjective endeavor to delve into the motivations behind why advocates push for specific reforms. It is also ultimately irrelevant to the legitimacy of the reforms proposed, which stand or fall on their own merits. ${ }^{91}$ However, the unintended consequences of anti-death penalty activism are of note. As the Supreme Court explained in Glossip, "antideath-penalty advocates pressured pharmaceutical companies to refuse to supply the drugs used to carry out death sentences." 92 This resulted in the use of alternative, untested drugs, which - at least according to some antideath penalty advocates - are responsible for inmates experiencing excruciatingly painful deaths. ${ }^{93}$ The potential for extreme pain experienced by executed inmates may ultimately benefit the anti-death penalty cause in the long run..$^{94}$ But this potential abolitionist benefit would have to be weighed against the harm of allegedly causing current inmates to endure so much pain. It provokes numerous ethical considerations to use humans as a temporary means to an ultimate end. ${ }^{95}$

This Essay makes no claims as to the underlying rationale behind Moran's passion for promoting firing squads. However, the questionable evidence and logic necessary to make the claim that the firing squad is preferable to lethal injection does invite questions about potential

89. Id. at 301.

90. Id. at 297

91. Pointing to the questionable motives of a person who proposes a reform in an effort to argue against the reform is a textbook example of the genetic fallacy, which states that it is fallacious to argue against something based on its origin. To be clear, this section does not argue against the firing squad based on the potential motivations of those who promote its use. Rather, this section only discusses the interesting history - and potential future - of the consequences of anti-death penalty advocacy.

92. Glossip, 576 U.S. at 870.

93. Id. at 976 (Sotomayor, J., dissenting).

94. Sensationalist claims in the media about inmates experiencing extreme pain from the use of untested drugs may cause the death penalty to lose popular support and ultimately be abolished.

95. Note that this assessment does not assume that any one anti-death penalty advocate intentionally worked toward making lethal injection drugs inaccessible to intentionally cause death row inmates more pain in their executions. The thought process may have gone no further than simply, "I think lethal injection is bad. Lethal injection uses certain drugs. Therefore, I will work to limit access to those drugs." Regardless of the foresight involved, the end result of inmates being executed by untested drugs remains the same. 
underlying motivations. It must be noted that, by promoting a method of execution that has less public support, ${ }^{96}$ this advocacy could be an effective method for abolishing the death penalty. Others have made comments that seem to imply that if the gut-level reaction from a firing squad execution is worse than that of lethal injection, then we should not have any executions. For example: "If we, as a society, cannot stomach the splatter from an execution carried out by firing squad, then we shouldn't be carrying out executions at all." ${ }^{, 97}$ As with the previously discussed issue of lethal injection drug availability, the balance of current inmates potentially suffering from a firing squad in order to eventually gain death penalty abolition invites numerous ethical considerations.

Another unintended, and often overlooked, consequence involving the death penalty is how abolition would result in fewer appellate protections for those convicted of particularly heinous crimes. This is because those on death row receive greater access to appellate review than those who are sentenced to life in prison. ${ }^{98}$

\section{CONCLUSION}

As the multitude of reasons provided in this Essay demonstrate, it is no surprise that firing squads have never been the preferred method of execution in the United States. ${ }^{99}$ Hurling projectiles toward an inmate in the hopes of causing cardiac failure, asphyxiation, or some other condition that will result in death, is far from an exact science. Moran's analysis unjustifiably makes lethal injection appear worse than it really is, makes the firing squad appear better than it really is, and therefore creates a false narrative that the firing squad is preferable to lethal injection. Furthermore, highly relevant issues from the discussion are omitted, such as the unsettled issue of the constitutionality of firing squads. Those promoting firing squads over lethal injection with the goal of abolishing the death penalty altogether are well advised to consider the consequences of such a strategy. Regardless of whether this is Moran's ultimate goal, her article falls short of making a persuasive argument to move away from lethal injection and toward firing squads as a means of performing executions.

96. National Polls and Studies, DEATH PENALTY INFO. CTR., https://deathpenaltyinfo.org/factsand-research/public-opinion-polls/national-polls-and-studies [https://perma.cc/LU37-KY58] (reporting the findings of a 2015 study that found $53 \%$ of Americans view the firing squad to be cruel and unusual, while only $16 \%$ view lethal injection as cruel and unusual).

97. Wood v. Ryan, 759 F.3d 1076, 1103 (9th Cir. 2014) (Kozinski, C.J., dissenting),

98. Jonathan Simon, Why Death-Row Inmates Oppose Life Without Parole, U.C. BERKELEY: BLOG (Sept. 25, 2012), https://blogs.berkeley.edu/2012/09/25/why-death-row-inmates-oppose-lifewithout-parole/ [https://perma.cc/ZQ5T-UKL8].

99. Moran, supra note 1, at 287. 